\title{
Dietary Intakes and Food Sources of Fatty Acids for Belgian Women, Focused on n-6 and n-3 Polyunsaturated Fatty Acids
}

\author{
Isabelle A. Sioen ${ }^{a, b}, *$, Ilse Pynaert ${ }^{a}$, Christophe Matthys ${ }^{a}$, Guy De Backer ${ }^{a}$, \\ John Van Camp ${ }^{b}$, and Stefaan De Henauw ${ }^{a}$ \\ Departments of ${ }^{a}$ Public Health and ${ }^{b}$ Food Safety and Food Quality, Ghent University, Ghent, Belgium
}

\begin{abstract}
The intake of fat, saturated and monounsaturated FA (SFA and MUFA), and omega- 6 and omega-3 PUFA has been estimated in 641 Belgian women (age 18-39 y). Their food intake was recorded using a 2-d food diary. The PUFA included were linoleic (LA), alpha-linolenic (LNA), arachidonic (AA), eicosapentaenoic (EPA), docosapentaenoic (DPA) and docosahexaenoic (DHA) acids. The mean total fat intake corresponded to $34.3 \%$ of total energy intake (E). The mean intake of the FA groups corresponded to $13.7 \%, 13.1 \%$, and $6.0 \%$ of $E$, for SFA, MUFA, and PUFA, respectively. The mean intake of LA was $5.3 \%$ of $E$ and of LNA was $0.6 \%$ of $E$, with a mean LA/LNA ratio of 8.7 . The mean intake of AA was $0.03 \%$ of $E$. The mean intake of EPA, DPA, and $\mathrm{DHA}$ was $0.04 \%, 0.01 \%$, and $0.06 \%$ of $\mathrm{E}$, respectively. According to the Belgian recommendations, the total fat and SFA intake was too high for about three-quarters of the population. The mean LA and overall n-6 PUFA intake corresponded with the recommendation, with part of the population exceeding the upper level. Conversely, the population showed a large deficit for LNA and n3 PUFA. The major food source for LA and LNA was fats and oils, followed by cereal products. The main sources of long-chain PUFA were fish and seafood, and meat, poultry, and eggs. From a public health perspective, it seems desirable to tackle the problem of low n-3 PUFA intake.

Paper no. L9945 in Lipids 41, 415-422 (May 2006).
\end{abstract}

Advances in the knowledge concerning physiological functions of dietary PUFA, in particular omega-3 PUFA, have led to an increased interest in the food sources and the level of dietary intake of these nutrients. Alpha-linolenic acid (LNA, C18:3n3 ) is a plant-derived omega-3 FA. Together with linoleic acid (LA, C18:2n-6), LNA is one of the two essential FA in the human diet; LA and LNA cannot be synthesised by the human metabolism. LNA can be desaturated and elongated in the human body to its longer-chain relatives, long-chain n-3 PUFA (LC n-3 PUFA), but the efficiency of this conversion is reduced by high intake levels of LA, which competes more effectively than LNA for desaturation and elongation enzymes because

*To whom correspondence should be addressed at Department of Public Health, Ghent University, UZ-2 Blok A, De Pintelaan 185, B-9000 Ghent, Belgium. E-mail: isabelle.sioen@ugent.be

Abbreviations: AA, arachidonic acid; DPA, docosapentaenoic acid; E, total energy intake; FCDB, food composition database; long-chain PUFA (LC PUFA); linoleic acid (LA); alpha-linolenic acid (LNA); MUFA, monounsaturated FA; SFA, saturated FA.
LA is abundantly present in Western diets (1). There is evidence to suggest that the conversion rate of dietary LNA to LC $n$-3 PUFA is insufficient to achieve adequate levels, even when the LNA intake is increased $(2,3)$. Nevertheless, a British study suggested that women may possess a greater capacity for LNA conversion than men $(4,5)$. LC n-3 PUFA are not synthesised by plants, but they are present in animals and in the marine food chain, EPA (C20:5n-3), docosapentaenoic acid (DPA, C22:5n3 ), and DHA (C22:6n-3) being the most abundant in the human diet. It is via planktivorous fishes that LC n-3 PUFA enter the marine food chain and accumulate in seafood (2). Therefore, seafood products are excellent food sources of LC n-3 PUFA.

For more than 30 years, a lot of fundamental clinical and epidemiological research work has been done with regard to the relationship between n-3 FA and health, showing the potential role of n-3 PUFA from the diet in the prevention of several diseases, in particular cardiovascular diseases $(1,6,7)$. Moreover, the importance of an adequate intake of DHA, particularly during pregnancy, is stated, given the role of DHA in the development of visual functions and the nervous system. Because LC n-3 PUFA cannot be formed by human cells to a significant extent, most of the n-3 FA accumulated in the fetal tissue must originate from the maternal diet $(8,9)$. The knowledge about the beneficial effects of these FA has led to the formulation of dietary reference intakes for the absolute amount of PUFA, but also for the balanced intake of n-6 and n-3. In 2003, the Belgian Health Council formulated recommendations for FA intake for the Belgian population, expressed in percentages of total energy intake (Table 1) (10). However, there is a lack of information on the current dietary intakes and sources for the Belgian population. One of the reasons for this has been the lack of a sufficiently complete food composition database (FCDB) for FA (11). Up to now, dietary intake assessments of individual n- 6 and n-3 PUFA on a population level can be found for Japan (12,13), France (14), Norway (15), Australia $(11,16)$, and Germany (17).

The aim of this study is to determine the total intake of fat, FA groups, and in particular n- 6 and n-3 PUFA in a population sample of Belgian women of reproductive age, and to compare these intakes with the current Belgian recommendations (10). In addition, the main food sources of these FA have been identified. 
TABLE 1

Recommended Daily Intakes of Fat and FA, Formulated by the Belgian Health Council (10) ${ }^{a}$

\begin{tabular}{|c|c|}
\hline & Recommendations (\%E) \\
\hline Fat & $<30$ \\
\hline SFA & $<10$ \\
\hline MUFA & $>10$ \\
\hline PUFA & $5.3-10.0$ \\
\hline $18: 2 n-6$ & $>2.0$ \\
\hline $20: 4 n-6$ & - \\
\hline इn-6 PUFA & $4.0-8.0$ \\
\hline $18: 3 n-3$ & $>1.0$ \\
\hline$\Sigma(20: 5 n-3,22: 6 n-3)$ & $>0.3$ \\
\hline$\Sigma \mathrm{n}-3$ PUFA & $1.3-2.0$ \\
\hline
\end{tabular}

\section{MATERIALS AND METHODS}

Population sample. The data reported in this paper are from a large epidemiological survey that included women aged 18 to $39 \mathrm{y}$. A total of 4,000 women were randomly selected from the population register of Ghent, a medium-sized city (a population of 229,000 inhabitants) in Flanders, the Dutch-speaking, northern part of Belgium. They were invited to participate in the study by postal mail and were asked to reply by use of an enclosed postcard. Not less than 2,634 subjects declined the invitation to participate, and 424 invitation letters were declared undeliverable by the postal service. Women who were pregnant, who had moved to another city, who did not speak Dutch, who were unable to come to the research center, or who were unable to volunteer within the planned period of the fieldwork were excluded from the study. In total, dietary data were collected for 641 women. The primary objective of the survey was to evaluate food and nutrient (in particular iron) intake in a group of Belgian women of reproductive age. Dietary assessment was done on the basis of a 2-d food record, using diaries with a semistructured, open-entry format and consisting of six eating occasions: breakfast, lunch, dinner, and morning, afternoon, and evening snacks. The women were asked to give a detailed description of the foods eaten, if possible to give a brand name and to estimate the amounts using natural measures (e.g., pieces, slices) or household measures (e.g., coffee spoon, cup). Experienced dietitians used a standardized protocol, including a manual on household weights and measures, to convert the estimated amounts into weights. In addition, a general sociodemographic questionnaire was administered. Data were gathered during the year 2002 (January 29 to December 22), thereby covering the different seasons. The study was approved by the Ethical Committee of the Ghent University Hospital. Only the data from the 2-d food record are used in this study for assessing the intake of total fat and important dietary FA.

$F C D B$. A specific FCDB was developed on the basis of existing food composition data. Of all the different food items in the study $(n=1,063), 75.1 \%$ contained fat $(n=799)$. Total fat contents for these foods were available from the Belgian FCDB (18) and the Dutch FCDB (19). For the establishment of a detailed FA database, including SFA, MUFA, PUFA, LA, LNA, AA, EPA, DPA, and DHA, the following eight different exist- ing food composition tables were used: an extended version of the Dutch FCDB (20) (for 457 food items); a specific French FCDB (14) (for 115 food items); the British McCance \& Widdowson's FCDB (21) (for 59 food items); the USDA National Nutrient Database (22) (for 51 food items); the Finnish FCDB (23) (for 12 food items); the Canadian Nutrient File (24) (for 9 food items); the Danish FCDB (25) (for 6 food items); and the German Food Composition and Nutrition Table (26) (for 1 food item). Furthermore, food composition information from industries was used for 43 food items, mostly specific varieties of margarine, cheese, and dressings. Finally, for 46 composite food items, the FA composition was calculated using both local recipes describing the different ingredients and their proportions, and the FA composition of the ingredients as found in one of the FCDB. Detailed FA profiles for the 799 food items were then compiled using the listed databases by applying the proportional share of each FA (group) in the total fat content as found in the database of origin, to the total fat content of the food as listed in the local FCDB $(18,19)$.

Statistics. The population intake is calculated and expressed as means, standard deviations, and different percentiles (P5, P50, P95). All statistics are based on the mean of $2 \mathrm{~d}$ for each individual. The intakes are expressed in absolute amounts ( $\mathrm{g}$ or mg per d) as well as in percentage of total energy intake. The percentages of the n- 6 and n-3 PUFA provided by the different food items were calculated. These percentages were calculated as population proportions, as defined by Krebs-Smith et al. (27). The population proportion is calculated by summing the amount of a certain FA from a certain food item for all individuals and then dividing that by the sum of that FA from all food items for all individuals. The food items were grouped in eight different food groups, each consisting of several subgroups, as presented by Astorg et al. (14).

\section{RESULTS}

The intakes of total fat, SFA, MUFA, and PUFA of Belgian women $(n=461)$ are given in Table 2 in grams per day $(\mathrm{g} / \mathrm{d})$ and in percentage of total energy intake $(\% \mathrm{E})$. This table also shows the energy intake $(\mathrm{kJ} / \mathrm{d})$. The intakes of individual PUFA expressed in $\mathrm{mg} / \mathrm{day}$ and in $\% \mathrm{E}$ can be found in Table 3 . The mean $\mathrm{E}$ of the study population was $8,338 \mathrm{~kJ}$. On average, $34.3 \% \mathrm{E}$ was provided by fat intake. The mean intake of SFA and MUFA was very similar, respectively $13.7 \%$ and $13.1 \% \mathrm{E}$, whereas the mean intake of PUFA was less than half of it, being $6.0 \% \mathrm{E}$ (Table 2). Flemish women consumed on average 11.92 and $1.44 \mathrm{~g}(5.28$ and $0.64 \% \mathrm{E})$ of LA and LNA, respectively, per day. As a consequence, the LA/LNA ratio was fairly high: 8.7 on average, with $50 \%$ of the population having a ratio over 10.1 (Table 4). The mean daily intake for AA amounted to 55.9 $\mathrm{mg}(0.03 \% \mathrm{E})$. Mean intakes for EPA, DPA and DHA were 77.8 $\mathrm{mg} / \mathrm{d}(0.04 \% \mathrm{E}), 25.3 \mathrm{mg} / \mathrm{d}(0.01 \% \mathrm{E})$ and $131.2 \mathrm{mg} / \mathrm{d}$ $(0.06 \% \mathrm{E})$, respectively (Table 3$)$. The average total n-6 PUFA intake (sum of LA and AA, presented as $\sum \mathrm{n}-6 \mathrm{PUFA}$ ) was 11.97 g/d (5.33\%E). Mean total n-3 PUFA intake (sum of LNA, EPA, DPA, and DHA, presented as $\sum \mathrm{n}-3$ PUFA) was $1.67 \mathrm{~g} / \mathrm{d}$ $(0.75 \% \mathrm{E})$. As a result, the mean ratio of $\sum \mathrm{n}-6$ PUFA to $\sum \mathrm{n}-3$ 
TABLE 2

Intake of Energy, Total Fat, and the Three Different FA Groups

\begin{tabular}{|c|c|c|c|c|c|c|c|c|c|}
\hline & Energy Intake & Total Fat & SFA & MUFA & PUFA & Total Fat & SFA & MUFA & PUFA \\
\hline & $\mathrm{kJ} / \mathrm{d}$ & \multicolumn{4}{|c|}{$\mathrm{g} / \mathrm{d}$} & \multicolumn{4}{|c|}{$\% \mathrm{E}$} \\
\hline Mean & 8,338 & 77.6 & 30.9 & 29.6 & 13.4 & 34.3 & 13.7 & 13.1 & 6.0 \\
\hline $\mathrm{SD}$ & 2,076 & 27.9 & 12.1 & 11.7 & 6.4 & 6.9 & 3.4 & 3.3 & 2.3 \\
\hline 5th percentile & 5,115 & 36.2 & 13.5 & 13.3 & 4.7 & 22.6 & 7.9 & 7.9 & 2.7 \\
\hline Median & 8,243 & 75.3 & 29.2 & 28.4 & 12.6 & 34.4 & 13.7 & 12.9 & 5.7 \\
\hline 95th percentile & 11,964 & 125.6 & 52.3 & 50.4 & 25.0 & 45.4 & 19.2 & 18.8 & 10.0 \\
\hline
\end{tabular}

TABLE 3

Intakes of Individual PUFA

\begin{tabular}{|c|c|c|c|c|c|c|c|c|c|}
\hline & $18: 2 n-6$ & $18: 3 n-3$ & $20: 4 n-6$ & $20: 5 n-3$ & $22: 5 n-3$ & $22: 6 n-3$ & $\Sigma \mathrm{n}-6$ PUFA & $\Sigma(20: 5 n-3,22: 6 n-3)$ & $\Sigma$ n-3 PUFA \\
\hline & \multicolumn{9}{|c|}{$\mathrm{mg} / \mathrm{d}$} \\
\hline Mean & $1,1918.8$ & $1,436.9$ & 55.9 & 77.8 & 25.3 & 131.2 & $1,1974.8$ & 208.9 & $1,671.2$ \\
\hline SD & $5,859.5$ & 902.6 & 47.4 & 156.1 & 45.7 & 246.9 & $5,869.1$ & 396.6 & $1,005.4$ \\
\hline 5th percentile & $3,915.0$ & 432.2 & 3.6 & 0.0 & 0.0 & 0.0 & $3,938.5$ & 0.0 & 532.1 \\
\hline Median & $1,1079.3$ & $1,258.5$ & 43.8 & 14.0 & 11.7 & 42.5 & $11,113.8$ & 54.1 & $1,445.8$ \\
\hline \multirow[t]{2}{*}{ 95th percentile } & $2,2778.4$ & $3,030.5$ & 147.9 & 427.7 & 100.2 & 647.1 & $22,798.5$ & $1,115.4$ & $3,558.1$ \\
\hline & \multicolumn{9}{|c|}{$\% \mathrm{E}$} \\
\hline Mean & 5.28 & 0.64 & 0.03 & 0.04 & 0.01 & 0.06 & 5.33 & 0.10 & 0.75 \\
\hline SD & 2.08 & 0.34 & 0.02 & 0.07 & 0.02 & 0.11 & 2.12 & 0.18 & 0.40 \\
\hline 5th percentile & 2.39 & 0.24 & 0.00 & 0.00 & 0.00 & 0.00 & 2.40 & 0.00 & 0.29 \\
\hline Median & 5.04 & 0.57 & 0.02 & 0.01 & 0.01 & 0.02 & 5.07 & 0.02 & 0.66 \\
\hline 95th percentile & 9.05 & 1.32 & 0.07 & 0.18 & 0.05 & 0.28 & 9.00 & 0.44 & 1.53 \\
\hline
\end{tabular}

For abbreviations, see Table 1.

PUFA was 7.8. The 5th and 95th percentiles of this ratio show a quite high variation (Table 4). The contribution of the LC n-6 derivates to the $\sum$ n-6 PUFA was on average very low, only $0.5 \%$. For the $\sum \mathrm{n}-3$ PUFA, the LC fraction accounted for $14.0 \%$. Furthermore, the LC PUFA intake is skewed to the right, as shown by the median intakes being much lower than the mean intakes (Table 3 ). A large proportion of the study population had no intake of the LC PUFA on both recorded days, whereas others had rather high intakes.

The percentages of fat, SFA, MUFA, total PUFA, and individual $n-6$ and $n-3$ PUFA provided by different food types are presented in Tables 5 and 6 . The major food sources contributing to total fat intake were dairy products, sweet products, fats and oils, and meat, poultry, and eggs. Dairy products and sweet products were the main contributors to SFA intake, whereas fats and oils were the primary source of MUFA and PFUA (Table 5). Fats and oils were the main sources for LA (31\%) and especially of LNA (45\%), followed by cereal products. In the group of fats and oils, margarines and fatty sauces (dressings, etc.) were the major subgroups. Breads was the most important subgroup in the groups of cereal products. The intake of AA was mainly contributed to the diet by meat, poultry, and eggs, which contributed more than half of the intake. The subgroup eggs was responsible for more than $25 \%$ of the overall AA intake. The second important contributor was fish and seafood, accounting for $17.8 \%$, with molluscs and crustacean as the most important subgroup, followed by fatty fish. For the three different LC n-3 PUFA taken into consideration in this study, a nearly equivalent pattern is
TABLE 4

Ratio of the Intake of LA versus LNA and of the Intake of $n-6$ PUFA versus n-3 PUFA

\begin{tabular}{lcc}
\hline & $18: 2 \mathrm{n}-6 / 18: 3 \mathrm{n}-3$ & $\Sigma \mathrm{n}-6$ PUFA/ $\Sigma \mathrm{n}-3$ PUFA \\
\hline Mean & 8.7 & 7.8 \\
SD & 5.4 & 4.2 \\
5th percentile & 5.3 & 4.2 \\
Median & 10.1 & 8.8 \\
95th percentile & 19.0 & 16.4 \\
\hline
\end{tabular}

For abbreviations, see Table 1.

found concerning the contribution of the different food groups to the mean intake. Fish and seafood contributed $87.3 \%, 66.0 \%$, and $80.0 \%$, respectively, of EPA, DPA, and DHA. The most important subgroup was fatty fish, which accounted for almost half

TABLE 5

Food Sources for Total Fat and the Three FA Groups (\% of Contribution)

\begin{tabular}{lrrrr}
\hline Food Group & Fat & SFA & MUFA & PUFA \\
\hline Total cereal products & 8.9 & 8.7 & 8.2 & 12.3 \\
Total dairy products & 19.7 & 31.0 & 14.9 & 3.0 \\
Total fats and oils & 18.5 & 9.9 & 22.1 & 31.7 \\
Total fish and seafood & 1.7 & 0.9 & 1.7 & 2.8 \\
Total fruits and vegetables & 9.3 & 5.8 & 10.9 & 13.3 \\
Total meat, poultry, and eggs & 15.4 & 14.3 & 17.1 & 12.2 \\
Total miscellaneous & 7.5 & 4.5 & 8.3 & 12.8 \\
Total sweet products & 19.1 & 24.9 & 16.7 & 11.9 \\
\hline
\end{tabular}


TABLE 6

Contribution of Food Sources to n-6 and n-3 PUFA Intakes (\% of the Total Intake of Each FA Brought by Each Food Group: Means of the Whole Population Sample)

\begin{tabular}{|c|c|c|c|c|c|c|c|c|}
\hline Food Groups & $\mathrm{LA}$ & LNA & $\mathrm{AA}$ & EPA & DPA & $\mathrm{DHA}$ & $\sum n-6^{a}$ & $\Sigma \mathrm{n}-3^{b}$ \\
\hline Breads & 12.9 & 9.9 & 0.0 & 0.0 & 0.0 & 0.0 & 12.8 & 8.5 \\
\hline Breakfast cereals & 1.1 & 0.5 & 0.2 & 0.0 & 0.0 & 0.0 & 1.1 & 0.4 \\
\hline Cereal-based dishes & 0.8 & 1.4 & 0.7 & 0.0 & 0.0 & 0.1 & 0.8 & 1.2 \\
\hline Pasta, rice, and other cereals & 1.6 & 1.3 & 0.6 & 0.4 & 0.0 & 0.2 & 1.6 & 1.2 \\
\hline Total cereal products & 16.4 & 13.1 & 1.6 & 0.4 & 0.0 & 0.3 & 16.3 & 11.3 \\
\hline Butter & 0.3 & 0.9 & 1.2 & 0.0 & 0.0 & 0.0 & 0.3 & 0.8 \\
\hline Cheese & 1.2 & 4.4 & 4.3 & 0.0 & 0.0 & 0.0 & 1.3 & 3.7 \\
\hline Cream & 0.1 & 0.5 & 0.0 & 0.0 & 0.0 & 0.0 & 0.1 & 0.4 \\
\hline Milk & 0.2 & 0.6 & 0.4 & 0.0 & 0.0 & 0.0 & 0.2 & 0.6 \\
\hline Yogurts & 0.1 & 0.2 & 0.0 & 0.0 & 0.0 & 0.0 & 0.1 & 0.2 \\
\hline Total dairy products & 1.9 & 6.6 & 5.9 & 0.0 & 0.0 & 0.0 & 2.0 & 5.6 \\
\hline Fatty sauces & 11.3 & 25.1 & 0.0 & 0.1 & 0.1 & 0.0 & 11.2 & 21.6 \\
\hline Margarines & 15.7 & 17.7 & 0.0 & 0.9 & 0.0 & 0.5 & 15.6 & 15.3 \\
\hline Mixed fats & 0.1 & 0.2 & 0.0 & 0.0 & 0.0 & 0.0 & 0.1 & 0.1 \\
\hline Vegetable oils & 4.3 & 1.8 & 0.0 & 0.0 & 0.0 & 0.0 & 4.3 & 1.6 \\
\hline Total fats and oils & 31.4 & 44.7 & 0.0 & 1.1 & 0.1 & 0.5 & 31.2 & 38.6 \\
\hline Fatty fish & 0.4 & 0.6 & 5.0 & 47.4 & 49.8 & 48.1 & 0.4 & 7.3 \\
\hline Fish products & 0.4 & 0.1 & 0.4 & 3.2 & 1.9 & 3.0 & 0.4 & 0.5 \\
\hline Half-fatty fish & 0.0 & 0.0 & 1.2 & 5.2 & 3.8 & 6.6 & 0.0 & 0.8 \\
\hline Lean fish & 0.0 & 0.0 & 2.2 & 7.6 & 4.5 & 9.5 & 0.0 & 1.2 \\
\hline Molluscs and crustaceans & 0.0 & 0.1 & 8.9 & 23.9 & 6.1 & 12.9 & 0.1 & 2.3 \\
\hline Total fish and seafood & 0.8 & 0.9 & 17.8 & 87.3 & 66.0 & 80.0 & 0.9 & 12.1 \\
\hline Fruits & 0.0 & 0.4 & 0.0 & 0.0 & 0.0 & 0.0 & 0.0 & 0.4 \\
\hline Legumes & 0.1 & 0.3 & 0.0 & 0.0 & 0.0 & 0.0 & 0.1 & 0.3 \\
\hline Nuts and seeds & 6.6 & 3.5 & 0.0 & 0.6 & 0.0 & 0.0 & 6.6 & 3.1 \\
\hline Potatoes & 5.5 & 1.7 & 0.0 & 0.0 & 0.0 & 0.0 & 5.5 & 1.5 \\
\hline Soups & 0.6 & 0.6 & 0.8 & 0.1 & 0.0 & 0.2 & 0.6 & 0.5 \\
\hline Vegetables & 0.6 & 1.8 & 0.0 & 0.1 & 0.0 & 0.0 & 0.6 & 1.5 \\
\hline Total fruits and vegetables & 13.4 & 8.4 & 0.8 & 0.8 & 0.0 & 0.2 & 13.4 & 7.2 \\
\hline Eggs & 1.1 & 0.3 & 25.5 & 0.2 & 6.2 & 6.1 & 1.2 & 0.9 \\
\hline Meat and meat dishes & 8.4 & 8.3 & 17.9 & 2.4 & 12.1 & 2.0 & 8.5 & 7.6 \\
\hline Poultry & 1.6 & 1.2 & 15.3 & 2.7 & 12.9 & 3.7 & 1.6 & 1.7 \\
\hline Total meat, poultry, and eggs & 11.1 & 9.9 & 58.7 & 5.2 & 31.2 & 11.8 & 11.3 & 10.1 \\
\hline Biscuits & 2.9 & 2.7 & 0.2 & 0.0 & 0.0 & 0.0 & 2.8 & 2.4 \\
\hline Chocolate products & 5.4 & 3.7 & 0.0 & 0.0 & 0.0 & 0.0 & 5.4 & 3.2 \\
\hline Pastry and desserts & 4.5 & 4.4 & 8.7 & 0.1 & 0.1 & 0.9 & 4.5 & 3.8 \\
\hline Sugar and sweets & 0.1 & 0.0 & 0.0 & 0.0 & 0.0 & 0.0 & 0.1 & 0.0 \\
\hline Total sweet products & 12.8 & 10.8 & 9.0 & 0.1 & 0.1 & 0.9 & 12.8 & 9.3 \\
\hline Dietetic products & 0.0 & 0.0 & 0.0 & 0.0 & 0.0 & 0.0 & 0.0 & 0.0 \\
\hline Miscellaneous & 0.1 & 0.0 & 0.0 & 0.0 & 0.0 & 0.0 & 0.1 & 0.0 \\
\hline Salty snacks & 2.2 & 0.7 & 0.0 & 0.0 & 0.2 & 0.0 & 2.1 & 0.6 \\
\hline Snacks & 6.8 & 2.9 & 6.2 & 4.3 & 2.3 & 6.2 & 6.8 & 3.2 \\
\hline Soydrink & 0.0 & 0.0 & 0.0 & 0.0 & 0.0 & 0.0 & 0.0 & 0.0 \\
\hline Spices and condiments & 0.5 & 0.8 & 0.0 & 0.0 & 0.0 & 0.0 & 0.5 & 0.7 \\
\hline Vegetarian substitute & 2.6 & 1.3 & 0.0 & 0.8 & 0.0 & 0.0 & 2.6 & 1.2 \\
\hline Total miscellaneous & 12.1 & 5.8 & 6.2 & 5.1 & 2.5 & 6.2 & 12.1 & 5.7 \\
\hline
\end{tabular}

${ }^{a} \Sigma \mathrm{n}-6=\mathrm{C} 18: 2 \mathrm{n}-6+\mathrm{C} 20: 4 \mathrm{n}-6$.

$b_{\Sigma n-3}=\mathrm{C} 18: 3 n-3+C 20: 5 n-3+C 22: 5 n-3+C 22: 6 n-3$.

of the overall intake of EPA, DPA, and DHA. For EPA, the subgroup molluscs and crustacean were also quite important (accounting for 23.9\%). A substantial part of the DPA intake was contributed by poultry $(13.0 \%)$, meat and meat dishes $(12.1 \%)$, and eggs (6.1\%). This group contributed also to the DHA intake (for $11.8 \%$ ), with eggs as the major subgroup $(6.1 \%)$. Since fortification of margarines with LC n-3 PUFA and since the use of eggs in pastry and desserts, as well as in certain snacks, these food items also contribute a bit to the intake of LC n-3 PUFA intake.

\section{DISCUSSION}

Some methodological shortcomings related to this study have to be mentioned. First, it has to be said that extreme intakes (low and high) are likely to be exaggerated because the consumption data were derived only from a 2-d food record. Two days are not enough to give a picture of the usual intake on an individual level, especially for nutrients abundantly present in foods that are not consumed on a daily basis, such as seafood products. There is a high within- and between-subject variance 


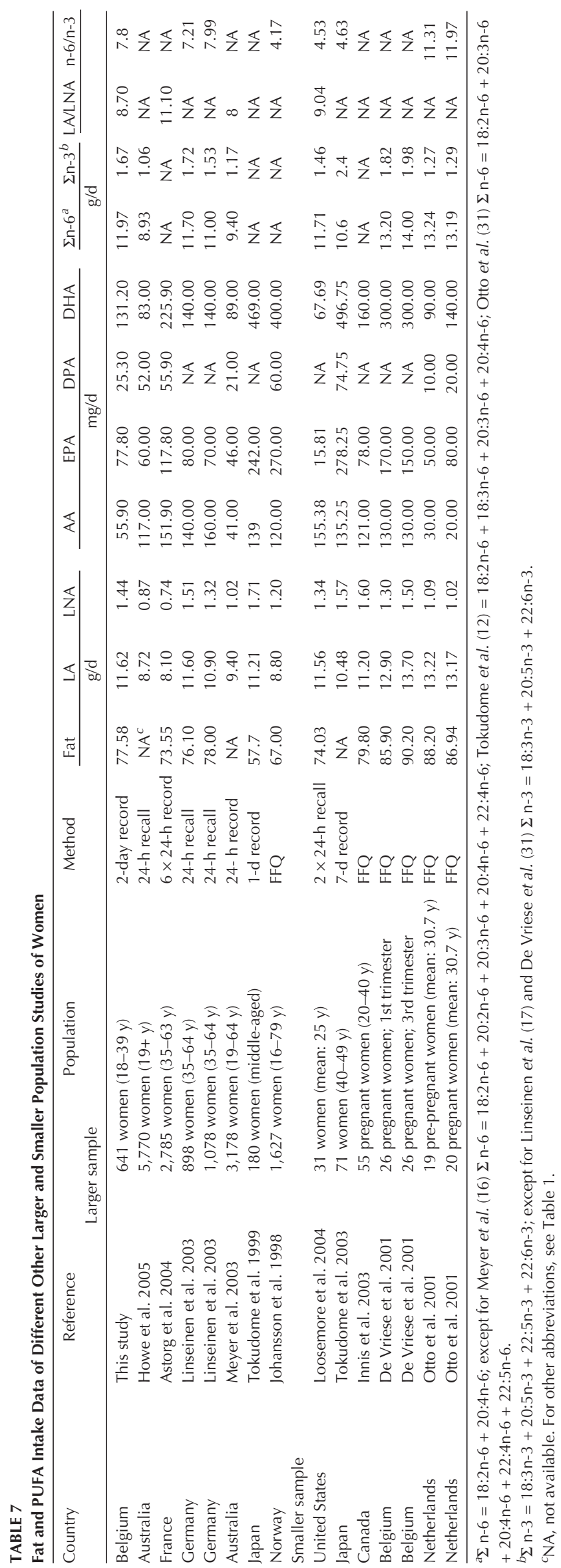

for these nutrient intakes over different days. Nelson et al. (28) calculated the days needed to assess the individual PUFA intake with a good correlation $(r \geq 0.9)$ between the observed and the true mean intake. For women older than $18 \mathrm{y}$, at least $30 \mathrm{~d}$ should be necessary. Nevertheless, the 2-d food record yields unbiased estimates of the mean food consumption of a population sample.

Second, at the level of the food composition data, a point of discussion is that PUFA, in particular the long-chain PUFA, are present in only small amounts in individual foods, but accumulate to significant levels of biological importance in the context of a whole diet. For most foods, these low values often round down to zero when reported to a single decimal place, and so it is likely that FA concentrations will be consistently underreported in FCDB (29). Furthermore, for some items it was not easy to find the FA composition. Quinoa, for example, was only mentioned in the German FCDB (26). We were obliged to use eight different databases in order to determine the FA composition of all food items, which is not an ideal situation. Moreover, a very recent Australian study (11) noted that the meat and poultry category of foods was a significant source of LC n-3 PUFA. The authors stated that the modest amount of PUFA in muscle tissue phospholipids of lean meat needs to be taken into account when determining dietary PUFA intakes. The majority of LC n-3 PUFA in meat is DPA. According to Howe et al. (11), the LC n-3 PUFA content of meat products has been underestimated up to now. Because of the limitations of available data about the FA content of these food items, LC n-3 intake from meat, poultry, and eggs, especially DPA intake, could have been underestimated, but this is not likely to have resulted in a significant underestimation of the mean EPA and DHA intake, given that these two FA are mainly brought by fish and seafood. Moreover, the Belgian recommendation considers only EPA and DHA for the evaluation of LC n-3 PUFA intake. Therefore, the evaluation of the intake data against the Belgian recommendations is not influenced by the possible underestimation of DPA during the intake assessment.

The recommendations formulated by the Belgian Health Council regarding fat and FA (Table 1), were used to evaluate the intakes of this study population. It is recommended that the total fat intake not exceed $30 \%$ of E per day. Three-quarters of the population exceeded the tolerable upper intake limit for total fat $(30 \% \mathrm{E})$ and SFA $(10 \% \mathrm{E})$, whereas MUFA and PUFA corresponded to the recommendations. In contrast to the intakes of LA and En-6 PUFA, which fit the recommendations for the major part of the population, the mean and median intakes of LNA and $\sum$ n-3 PUFA fell well below the recommended intake ( $1 \% \mathrm{E}$ for LNA). The same is true for LC n-3 PUFA. The recommended minimum is expressed for the sum of EPA and DHA, and is at least equal to $0.3 \% \mathrm{E}$. The mean intake for $\mathrm{EPA}+\mathrm{DHA}$ was $0.10 \% \mathrm{E}$, and the median was $0.20 \%$ E. It can be concluded that the study population has an important deficit for these FA.

Published data of mean dietary intake of PUFA in adult women, expressed in $\mathrm{g} / \mathrm{d}$ or $\mathrm{mg} / \mathrm{d}$, are presented in Table 7. 
Nevertheless, the comparisons must be interpreted with caution as survey methods can vary. Moreover, non-negligible differences exist in the age and the total energy intake of the population.

The women of the studies in France, Norway, and Australia seemed to consume less LA, whereas the women in Germany and Japan consumed quite similar levels (11,12,14-17). Conversely, higher absolute LA intake levels were found in another Belgian and a Dutch study with a smaller sample size $(30,31)$ (Table 7). Another pattern was found for LNA. The absolute intake of LNA determined in this study is quite high when compared with other studies, with exception of the Japanese and German studies $(12,17)$ and a study done in pregnant Canadian women (32). In all the other studies, a lower LNA intake was determined. This is remarkable, because even in the present study a comparison of the LNA intake with the Belgian recommendations showed a deficit of this FA in the diet of the Belgian women. Astorg et al. (14) translated the mean LNA intake of the female population group in their study into $\% \mathrm{E}$; it was $0.38 \% \mathrm{E}$. Comparing this with the Belgian recommended minimum level, the French women have an even worse deficit than the Belgian women. Correspondingly, the mean LA/LNA ratio of the French women is far higher (11.10) than the one found in this study. Whereas the essential n-6 PUFA intake seemed rather high in comparison with other studies, the opposite applies to the mean absolute intake of AA, the only LC n-6 PUFA taken into consideration in this study. Most of the other studies found a mean absolute AA intake that was two to three times higher than the mean AA intake determined in this study. Nevertheless, the intake of the food sources that contribute the most AA to the diet are equal compared with those found in the French and the Australian studies $(14,16)$; they are (1) meat, poultry, and eggs (accounting for more than $50 \%$ of the AA intake), and (2) fish and seafood. So a probable explanation is that the AA concentration of these food items is underestimated in the FCDBs that were used in this study.

A large variation is found in the intake estimations of LC n3 PUFA between studies and countries. As for LA and LNA mean intake, the mean LC n-3 PUFA intake is comparable with the results found in the German study (17), as well as with the results of the Dutch study (31). A larger absolute intake of EPA, DPA, and DHA is found in France and especially in Norway and Japan, probably due to larger seafood consumption. In this study, the average seafood consumption of the women (calculated as a mean of the $2 \mathrm{~d})$ was $27.0( \pm 44.9) \mathrm{g} / \mathrm{d}$. Welch et al. (33) reported the seafood consumption in 10 European countries for men and women between 35 and 74 years old. For women, a mean seafood consumption of $15.9 \mathrm{~g} / \mathrm{d}$ and $19.9 \mathrm{~g} / \mathrm{d}$ was found in two German cities, and a mean of $13.3 \mathrm{~g} / \mathrm{d}$ and $13.4 \mathrm{~g} / \mathrm{d}$ in two Dutch cities (33). In comparison, French women have a mean seafood consumption ranging between $35.0 \mathrm{~g} / \mathrm{d}$ and $52.4 \mathrm{~g} / \mathrm{d}$, depending on the region where they live; the mean intake of seafood for Norwegian women was $42.9 \mathrm{~g} / \mathrm{d}$ in south and east Norway and $63.3 \mathrm{~g} / \mathrm{d}$ in north and west Norway (33). Johansson et al. (15) reported a mean intake of $57 \mathrm{~g}$ of fish per day for Norwegian women. These results show that the higher seafood consumption in the latter two countries is clearly the main reason for the higher LC n-3 PUFA intake.

Comparisons of food sources of fat and FA are not easy, because the definitions of food groups are not the same in the different studies. The definition of the food groups in this study is based on the French study of Astorg et al. (14), so the results of these two studies are quite comparable. The comparison with other results must be seen as an indication.

The main sources for LA found in this study were fats and oils $(31.4 \%)$, followed by cereal products $(16.4 \%)$. The important contribution of fats and oils to the LA intake was also found in the French and the Australian studies (accounting for $33.5 \%$ and $21.9 \%$, respectively) $(14,16)$, as well as in the Japanese study (13). For AA, the intake was mostly contributed by meat, poultry, and eggs, followed by fish and seafood. The same results were found by the French and Australian authors: meat, poultry, and eggs accounted for $67.2 \%$ and $70.15 \%$, respectively, followed by fish and seafood $(11.1 \%$ and $27.2 \%$, respectively). In the Japanese study, chicken, eggs, and pork together contributed $50.6 \%$ to the AA intake.

In the present study, fats and oils were by far the major contributor to LNA intake (45\%), especially fatty sauces and margarines. This is at variance with the French study, where fats and oils were only a minor contributor (10\%), the major ones being dairy products, fruits and vegetables, and meat, poultry, and eggs (14). Fatty sauces and margarines seem to be much less consumed in France than in Belgium.

In this study, fish and seafood were the major contributors to the EPA, DPA, and DHA intake, representing respectively $87.3 \%, 66.0 \%$, and $80.0 \%$. In Norway, fish was also the major source (respectively, accounting for $55 \%, 43 \%$, and $57 \%$ ), followed by cod liver oil, which was used by $36 \%$ of the survey subjects (15). In contrast, cod liver oil, being rich in LC n-3 PUFA, was not consumed by the Belgian women included in this study. In the French data, fish and seafood were the major sources for EPA and DHA (72.0\% and $64.7 \%$, respectively) (14), but meat, poultry, and eggs were the first contributor of DPA intake (55\%). In Norway, meat and fish were the main sources of DPA (43\% each) (15). In the present study, the contribution of meat, poultry, and eggs to the DPA intake was lower (31\%). A very recent Australian publication described in detail the contribution of meat sources to the intake of LC n-3 PUFA (11). Their analyses showed that fish and seafood contributed $49.7 \%, 15.4 \%$, and $69.9 \%$ to the intake of, respectively, EPA, DPA, and DHA. On the other hand, meat, poultry, and game products provided, respectively, $44.8 \%, 73.2 \%$, and $19.6 \%$. This shows that an underestimation of the LC n-3 PUFA content of meat can be crucial, since the consumption of meat and meat products is large compared with that of fish and seafood.

\section{CONCLUSION}

In conclusion, analysis showed that the mean intake of total fat and SFA of Belgian women exceeded the Belgian recommendations. With regard to the PUFA intake, the mean intake of n-6 
PUFA seemed to be sufficient. In contrast, the mean intakes of LNA and LC n-3 PUFA were far too low. When considering these facts together, it seems advisable to explore ways to investigate food-based strategies to decrease the SFA intake and also increase the n-3 PUFA intake; this is a counterargument to the intake of supplements. Although such supplements can be an easy solution for some women, the presence of other nutrients in food sources of EPA and DHA, such as important amino acids and trace elements, must also be considered. This conclusion is in accordance with one of the conclusions in a recent Dutch report, which stated that an excessive intake of the unfavorable types of fat, such as SFA, increases the likelihood of developing cardiovascular disease by $25 \%$, whereas eating fish once or twice a week reduces this risk $25 \%$ (34).

A previous study in Belgium of consumer awareness and beliefs related to n-3 PUFA, their health benefits, and their food sources showed that awareness is poor and beliefs often wrong (35). Nutrition education should play an important role in convincing people of this dietary shift.

\section{ACKNOWLEDGMENTS}

The authors gratefully acknowledge financial support from the Belgian Science Policy through the SPSD II project CP/02/56, the Institute for the Promotion of Innovation through Science and Technology in Flanders (IWT-Vlaanderen), and the National Fund for Scientific Research/Flemish Division (Fund No G.0152.01). The dieticians Mrs. M. Bellemans and Mrs. M. De Maeyer (Department of Public Health, Ghent University) are thanked for their important contribution to the fieldwork and the data input of the food consumption data. The reviewers of this paper are thanked for their useful and detailed remarks and suggestions.

\section{REFERENCES}

1. Din, J.N., Newby, D.E., and Flapan, A.D. (2004) Science, Medicine, and the Future: Omega-3 Fatty Acids and Cardiovascular Disease-Fishing for a Natural Treatment, BMJ 328, 30-35.

2. Cunnane, S.C., and Griffin, B.A. (2002) Nutrition and Metabolism of Lipids, in Introduction to Human Nutrition, Gibney, M.J., Vorster, H.H., and Kok, F.J., eds., pp. 81-115, Blackwell Science, Oxford.

3. Li, D., Sinclair, A., Wilson, A., Nakkote, S., Kelly, F., Abedin, L., Mann, N., and Turner, A. (1999) Effect of Dietary AlphaLinolenic Acid on Thrombotic Risk Factors in Vegetarian Men, Am. J. Clin. Nutr. 69, 872-882.

4. Burdge, G.C., Jones, A.E., and Wootton, S.A. (2002) Eicosapentaenoic and Docosapentaenoic Acids Are the Principal Products of Alpha-Linolenic Acid Metabolism in Young Men, Br. J. Nutr. 88, 355-363.

5. Burdge, G.C., and Wootton, S.A. (2002) Conversion of AlphaLinolenic Acid to Eicosapentaenoic, Docosapentaenoic and Docosahexaenoic Acids in Young Women, Br. J. Nutr. 88, 411-420.

6. Ruxton, C.H., Reed, S.C., Simpson, M.J., and Millington, K.J. (2004) The Health Benefits of Omega-3 Polyunsaturated Fatty Acids: A Review of the Evidence, J. Hum. Nutr. Diet. 17, 449-459.

7. Ruxton, C. (2004) Health Benefits of Omega-3 Fatty Acids, Nurs. Stand. 18, 38-42.

8. Salem, N.J., and Pawlosky, R.J. (1992) Docosahexaenoic Acid Is an Essential Nutrient in the Nervous System, J. Nutr. Sci. Vitaminol. Spec No, 153-156.
9. Tanaka, Y., Funada, T., Hirano, J., and Hashizume, R. (1993) Triacylglycerol Specificity of Candida cylindracea Lipase: Effect of Docosahexaenoic Acid on Resistance of Triacylglycerol to Lipase, J. Am. Oil Chem. Soc. 70, 1031-1034.

10. Belgian Health Council. (2003) Voedingsaanbevelingen voor België. Herziene versie 2003. Belgian Health Council, Brussels.

11. Howe, P., Meyer, B., Record, S., and Baghurst, K. (2006) Dietary Intake of Long-Chain Omega-3 Polyunsaturated Fatty Acids: Contribution of Meat Sources, Nutrition 22, 47-53.

12. Tokudome, Y., Kuriki, K., Imaeda, N., Ikeda, M., Nagaya, T., Fujiwara, N., Sato, J., Goto, C., Kikuchi, S., Maki, S., and Tokudome, S. (2003) Seasonal Variation in Consumption and Plasma Concentrations of Fatty Acids in Japanese Female Dietitians, Eur. J. Epidemiol. 18, 945-953.

13. Tokudome, Y., Imaeda, N., Ikeda, M., Kitagawa, I., Fujiwara, N., and Tokudome, S. (1999) Foods Contributing to Absolute Intake and Variance in Intake of Fat, Fatty Acids and Cholesterol in Middle-Aged Japanese, J. Epidemiol. 9, 78-90.

14. Astorg, P., Arnault, N., Czernichow, S., Noisette, N., Galan, P., and Hercberg, S. (2004) Dietary Intakes and Food Sources of n6 and n-3 PUFA in French Adult Men and Women, Lipids 39, $527-535$.

15. Johansson, L.R.K., Solvoll, K., Bjorneboe, G.E.A., and Drevon, C.A. (1998) Intake of Very-Long-Chain n-3 Fatty Acids Related to Social Status and Lifestyle, Eur. J. Clin. Nutr. 52, 716-721.

16. Meyer, B.J., Mann, N.J., Lewis, J.L., Milligan, G.C., Sinclair, A.J., and Howe, P.R.C. (2003) Dietary Intakes and Food Sources of Omega-6 and Omega-3 Polyunsaturated Fatty Acids, Lipids 38, 391-398.

17. Linseisen, J., Schulze, M.B., Saadatian-Elahi, M., Kroke, A., Miller, A.B., and Boeing, H. (2003) Quantity and Quality of Dietary Fat, Carbohydrate, and Fiber Intake in the German EPIC Cohorts, Ann. Nutr. Metab. 47, 37-46.

18. NUBEL (Nutriënten België) (1999) Belgische voedingsmiddelentabel, 3rd edn., Ministerie van Volksgezondheid.

19. Beemster, C.J.M., van der Heijden, L.J.M., Hulshof, K.F.A.M., Langius, J.A.E., van Oosten, H.M., Pruissen-Boskaljon, J.C., and Westenbrink, S. (2001) Nevo-tabel. Nederlands voedingsstoffenbestand, pp. 1-298, Nederlands Voedingscentrum, The Hague.

20. Stichting NEVO. (2004) Nederlands Voedingsstoffenbestand 2003. Amsterdam, Voedingscentrum, Den Haag.

21. Food Standards Agency. (2002) McCance and Widdowson's. The Composition of Foods, 6th summary edn. Royal Society of Chemistry, Cambridge.

22. USDA National Data Laboratory. (2004) USDA National Nutrient Database for Standard Reference. Release 16-1. http://www.nalusda.gov/fnic/foodcomp

23. National Public Health Institute of Finland. (2004) Finnish Food Composition Database. http://www.fineli.fi

24. Health Canada. (2005) Canadian Nutrient File, version 2005. http://www.hc-sc.gc.ca/food-aliment/ns-sc/nr$\mathrm{rn} /$ surveillance/cnf-fcen/e_index.html

25. Danish Institute for Food and Veterinary Research, M.O.F.F.A.A. Danish Food Composition Databank (revision 6.0). http://www. foodcomp. dk

26. Souci, S.W., Fachmann, W., and Kraut, H. (2000) Food Composition and Nutrition Tables, 6th edn., pp. 1-1182, Scientific Publishers, Stuttgart.

27. Krebs-Smith, S.M., Kott, P.S., and Guenther, P.M. (1989) Mean Proportion and Population Proportion: Two Answers to the Same Question? J. Am. Diet. Assoc. 89, 671-676.

28. Nelson, M., Black, A.E., Morris, J.A., and Cole, T.J. (1989) Between- and Within-Subject Variation in Nutrient Intake from Infancy to Old Age: Estimating the Number of Days Required to Rank Dietary Intakes with Desired Precision, Am. J. Clin. Nutr. 50, 155-167. 
29. Mann, N.J., Sinclair, A.J., Percival, P., Lewis, J.L., Meyer, B.J., and Howe, P.R. (2003) Development of a Database of Fatty Acids in Australian Foods, Nutr. Diet. 60, 42-45.

30. De Vriese, S.R., De Henauw, S., De Backer, G., Dhont, M., and Christophe, A.B. (2001) Estimation of Dietary Fat Intake of Belgian Pregnant Women. Comparison of Two Methods, Ann. Nutr. Metab. 45, 273-278.

31. Otto, S.J., van Houwelingen, A.C., Badart-Smook, A., and Hornstra, G. (2001) Changes in the Maternal Essential Fatty Acid Profile During Early Pregnancy and the Relation of the Profile to Diet, Am. J. Clin. Nutr. 73, 302-307.

32. Innis, S.M., and Elias, S.L. (2003) Intakes of Essential n-6 and n-3 Polyunsaturated Fatty Acids Among Pregnant Canadian Women, Am. J. Clin. Nutr. 77, 473-478.

33. Welch, A.A., Lund, E., Amiano, P., Dorronsoro, M., Brustad, M., Kumle, M., Rodriguez, M., Lasheras, C., Janzon, L., Jansson, J., Luben, R., Spencer, E.A., Overvad, K., Tjonneland, A.,
Clavel-Chapelon, F., Linseisen, J., Klipstein-Grobusch, K., Benetou, V., Zavitsanos, X., Tumino, R., Galasso, R., BuenoDe-Mesquita, H.B., Ocke, M.C., Charrondiere, U.R., and Slimani, N. (2002) Variability of Fish Consumption Within the 10 European Countries Participating in the European Investigation into Cancer and Nutrition (EPIC) Study, Public Health Nutr. 5, 1273-1285.

34. van Kreijl, C.F., and Knaap, A.G.AC. (2004) Ons eten gemeten. Gezonde voeding en veilig voedsel in Nederland, Bilthoven, RIVM (Rijksinstituut voor Volksgezondheid en Milieu).

35. Verbeke, W., Sioen, I., Pieniak, Z., Van Camp, J., and De Henauw, S. (2005) Consumer Perception Versus Scientific Evidence About Health Benefits and Safety Risks from Fish Consumption, Public Health Nutr. 8, 422-429.

[Received February 17, 2006; accepted June 12, 2006] 